\title{
DINÂMICA DE OCUPAÇÃO ESPACIAL DE ÁREAS CONTÍGUAS (PERÍODO 1987-2008) E SUA RELAÇÃO COM TENSORES DE ORIGEMANTRÓPICANO MANGUEZAL DO RIO CACHOEIRA, ILHÉUS, BAHIA
}

\section{Spatial occupation dynamic of the adjacencies areas (period 1987-2008) and your relation with anthropic tensors in the mangrove forest at Cachoeira River, Ilhéus, Brazil}

Patrick Thomaz de Aquino Martins Doutorando em Geociências e Meio Ambiente pela Universidade Estadual Paulista Rio Claro/SP - Brasil patrick_thomaz@yahoo.com.br

Lilian de Lins Wanderley $\operatorname{Prof}^{\mathrm{a}} \mathrm{Dr}^{\mathrm{a}}$ da Universidade Federal de Sergipe São Cristóvão/SE - Brasil

lilianwanderley@uol.com.br

Artigo recebido para publicação em 24/02/09 e aceito para publicação em 17/07/09

RESUMO: O presente trabalho tem como objetivo identificar, por meio de técnicas de geoprocessamento, alterações espaciais ocorridas no manguezal do Rio Cachoeira, Ilhéus, Bahia, e áreas adjacentes, no periodo de 21 anos, correlacionando-as com elementos de origem antrópica. Foram identificadas e mapeadas quatro classes temáticas: manguezal, água, urbano e sistemas adjacentes. Ao longo dos anos houve o avanço da área urbana em detrimento das de manguezal e dos demais sistemas adjacentes, aumentando concomitantemente a pressão antrópica sobre os mangues. Problemas de ordem econômica e conseqüente flutuação da população no município ocasionaram a ocorrência de diversas formas de supressão do mangue, através de corte e aterramento, além de lançamento de resíduos de resíduos sólidos e outras intervenções associadas à baixa qualidade de vida no entorno do manguezal. Em contrapartida, houve a conservação de parte do mangue, devido ao dificil acesso na margem oposta à cidade e à presença de Reserva Particular do Patrimônio Natural. $O$ avanço das pressões antrópicas identificados no periodo e a atual situação vão contra a possibilidade de regeneração natural do ecossistema. Mesmo se eliminando o fator estresse, o metabolismo do sistema poderá apresentar implicações negativas irreversíveis. Permanecendo o ritmo e a forma de alteração registrada nos últimos anos, o ganho de território sobre os manguezais do Rio Cachoeira dificilmente será interrompido. Assim, o município ganha território, e perde um ecossistema de inestimável valor, podendo acarretar problemas sociais em futuro próximo.

Palavras-chave: Geotecnologia. Impacto ambiental. Biogeografia.

ABSTRACT: This work aims to identify, by geoprocessing techniques, spaces changes occurred in the Cachoeira River mangrove, Ilhéus, Bahia, and adjacent areas during the period of 21 years, correlating it with elements of anthropogenic origin. Four thematic categories were identified and mapped: mangrove, water, urban, and adjacent systems. Over the years there was the advance of the urban area at the expense of the mangrove and other adjacent systems, concurrently increasing the human 


\begin{abstract}
pressure on the mangroves. Problems of economic order and the consequent fluctuation of the population in the city caused the occurrence of various forms of suppression on the mangrove, such as cutting, landfill, launch of solid waste, etc. associated with low quality of life around the mangrove. In contrast, there was the conservation of the mangrove due to difficult access on the opposite shore of the city, in association with the presence of Private Reserve of Natural Heritage. The advancement of human pressures identified in the current situation go against the possibility of natural regeneration to the ecosystem. Even eliminated the stress factor, the metabolism of the system may present negative irreversible implications. Maintaining the pace and pattern of the recorded change in the last years, the gain of territory on the Cachoeira river mangroves hardly will be interruped in the coming years. Thus, the county gained territory and loses an inestimable and valuable ecosystem and can cause social problems in the near future
\end{abstract}

Keywords: Geotecnology. Environment impact. Biogeography.

\section{INTRODUÇÃO}

O crescimento urbano dos municípios litorâneos brasileiros tem acarretado uma série de impactos ao ecossistema manguezal. Isto ocorre por que esse crescimento acontece, na maioria das vezes, de forma desordenada e desorganizada. Em contrapartida, o espaço rural que detém áreas de mangue também contribui com ações degradantes, através da especulação imobiliária e do mau uso da bacia hidrográfica que vem se refletindo no estado atual desse ecossistema.

Mesmo com uma vasta legislação presente nas diversas esferas administrativas, as quais estabelecem ser o manguezal uma Área de Preservação Permanente (APP) e de estratégias para uso racional do meio litorâneo, contidos no Plano Nacional de Gerenciamento Costeiro Integrado (PNGC, 1990), é comum observar em áreas de mangue práticas supressivas da vegetação, presença de metais pesados pelo lançamento de efluentes industriais, alterações do oxigênio pelos despejos domésticos e inclusive eutrofização.

No município de Ilhéus, a ofensiva aos manguezais está atrelada ao processo histórico de (trans)formação do seu território. Durante décadas tem havido a incorporação de áreas de manguezal ao perímetro urbano do município, ao ponto de serem constituídos bairros sobre esses espaços, sobretudo voltados à população mais carente, como os bairros Nelson
Costa, Vila Nazaré, Nossa Senhora da Vitória, Teotônio Vilela, dentre outros (FIDELMAN, 2000). Esses bairros não são totalmente urbanizados, acarretando outros tipos de impactos ao ecossistema remanescente.

No caso específico do manguezal do Rio Cachoeira, maior e mais extenso manguezal do município, por possuir em seu limite áreas urbanas, rurais e periurbanas, há a convergência de impactos tanto do seu centro administrativo quanto da zona rural.

O entendimento do padrão de crescimento urbano e as formas de impacto resultantes são indicadores que podem ser utilizados como ferramentas de planejamento ambiental. Nesse sentido, o presente trabalho tem como objetivo identificar, por meio de técnicas de geoprocessamento, alterações espaciais ocorridas no manguezal do Rio Cachoeira e áreas adjacentes, no período de 21 anos, correlacionando tal dinâmica com elementos de origem antrópica não pertencentes ao sistema manguezal, que possam estar influenciando na sua dinâmica.

\section{2. ÁREA DE ESTUDO}

O Rio Cachoeira é o principal rio da bacia que leva o seu nome. Esta bacia está localizada no litoral sul do Estado da Bahia, entre as coordenadas $14^{\circ} 42^{\prime} /$ $15^{\circ} 20^{\prime} \mathrm{S}$ e $39^{\circ} 01^{\prime} / 40^{\circ} 09^{\prime} \mathrm{W}$, inserindo-se nas Bacias da Região Leste em escala estadual (SRH, 1996) e 
na Bacia do Atlântico Leste (CUNHA, 1998), em nível nacional.

Sua rede hidrográfica é composta pelos rios Colônia, Salgado e Cachoeira e seus tributários, e banha onze municípios (OLIVEIRA, 1997) onde habita uma população total estimada de cerca de 586.857 habitantes (IBGE, 2008).

O Rio Cachoeira é formado a partir da confluência dos rios Salgado e Colônia. Percorre uma extensão de cerca de 50 km (ROCHA FILHO, 1976; OLIVEIRA, 1994; 1997) e seu trecho médio banha os municípios de Itapé e Itabuna e seu trecho final, antes da sua embocadura, percorre um lugar denominado Coroa Grande, onde confluem os rios Santana e Itacanoeira, no município de Ilhéus. Seus principais afluentes são o rio Piabanha e o ribeirão Cinco Porcos (OLIVEIRA, 1997).

Todo o manguezal do Rio Cachoeira (FIG. 1) está situado no município de Ilhéus, o qual faz parte da zona fisiográfica Região Cacaueira, Região Econômica Litoral Sul da Bahia (SEPLANTEC/CEI, 1996) e possui uma população estimada de 220.144 habitantes em uma superfície de $1.841 \mathrm{~km}^{2}$ (IBGE, 2008).

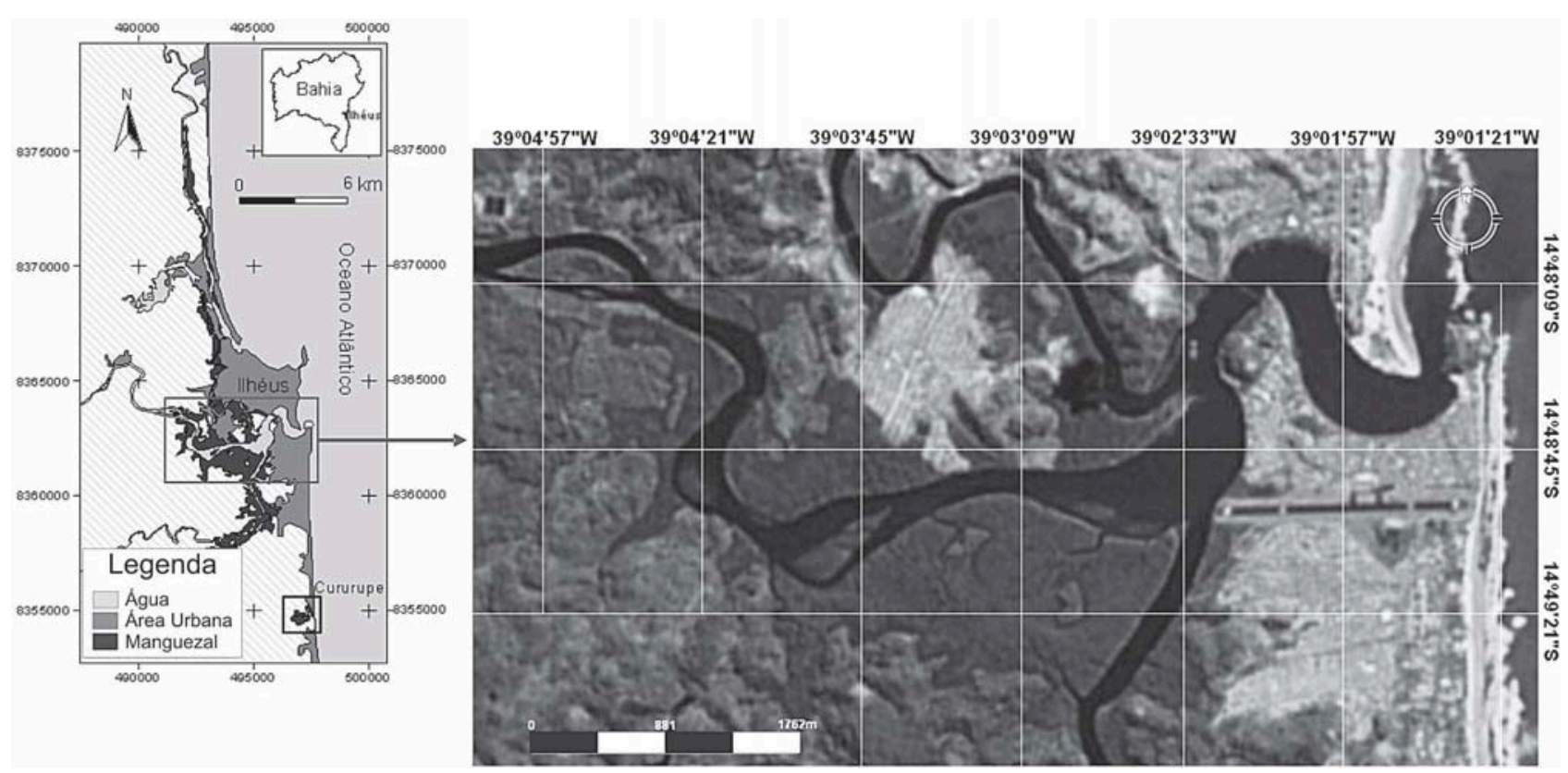

FIGURA 1. Manguezal do Rio Cachoeira.

Fonte: Adaptado de Martins \& Couto (2007) e Google (2007)

No município de Ilhéus o manguezal do Rio Cachoeira está distribuído longitudinalmente desde a baía do Pontal a proximidades do bairro Banco da Vitória, distante cerca de $10 \mathrm{~km}$ da baía, abrangendo uma área de aproximadamente 248 ha. (MARTINS \& COUTO, 2007).

O polígono da área de estudo foi delimitado de forma que abarcasse todo o manguezal do Rio Cachoeira e nesse espaço abrangeu também outros ecossistemas e categorias de uso do solo, dentre os quais
Mata Atlântica, cultivos agrícolas, sistemas aquáticos e a malha urbana da sede municipal de Ilhéus.

\section{MATERIAIS E MÉTODOS}

O estudo foi realizado em duas etapas. A primeira corresponde à aplicação de técnicas de geoprocessamento para o entendimento da dinâmica temporoespacial. A segunda compreendeu a identificação in loco de tensores atuantes sobre o sistema manguezal como se encontra hoje. 
Dinâmica de ocupação espacial de áreas contíguas (período 1987-2008) e sua relação com tensores de origem antrópica no manguezal do Rio Cachoeira, Ilhéus, Bahia

Patrick Thomaz de Aquino Martins, Lilian de Lins Wanderley

\subsection{Dinâmica temporo-espacial}

Foram utilizados os aplicativos SPRING (CÂMARA et al., 1996), versão 5.0.2, ENVI 4.3 e ArcGIS 9.1, quatro imagens do sensor TM/Landsat e um mosaico de imagens Landsat ortorretificadas. As imagens foram obtidas, respectivamente, a partir do catálogo de imagens do INPE - Instituto Nacional de Pesquisas Espaciais, e da NASA - National Aeronautics and Space Administration (QUAD. 1), via FTP, através de seus sítios oficiais na rede mundial de computadores, Internet.

Essas imagens estavam em extensão GeoTIFF e contavam com todas as bandas possíveis ao sensor. Através do acervo GeoCover (NASA, 2006) foi realizado o download do mosaico de imagens que correspondia a área de estudos (S-24-10_2000), no formato MrSID.

QUADRO 1. Imagens de satélites utilizadas na análise de dinâmica espacial.

\begin{tabular}{|lcccc|}
\hline Satélite & Sensor & Data de imageamento & Acervo & Data de aquisição \\
\hline Landsat 5 & TM & $09 / 05 / / 1987$ & Catálogo de Imagens INPE & $28-08-2006$ \\
Landsat 5 & TM & $28 / 05 / 1994$ & Catálogo de Imagens INPE & 03-06-2006 \\
Landsat 7 & ETM+ & $23 / 05 / 2001$ & Catálogo de Imagens INPE & $28-08-2006$ \\
Landsat 5 & TM & $03 / 06 / 2008$ & Catálogo de Imagens INPE & $01-02-2008$ \\
Landsat 7 & ETM+ & Mosaico 2000 & Catálogo GeoCover & $26 / 11 / 2007$ \\
\hline
\end{tabular}

No SPRING foi estabelecido um banco de dados gerenciado em dBase, com projeto na projeção UTM - Universal Transversa de Mercator, datum SAD-69 - South American Datum 1969, e retângulo envolvente nas coordenadas $14^{\circ} 59^{\prime} 33.00^{\prime \prime} \mathrm{e}$ $14^{\circ} 32^{\prime} 46.00^{\prime \prime}$ de latitude sul e $39^{\circ} 10^{\prime} 52.00^{\prime \prime}$ e $38^{\circ} 54^{\prime} 32.00^{\prime \prime}$ de longitude oeste.

Inicialmente foi realizada a restauração das imagens. A seguir estas foram exportadas no formato GeoTIFF e abertas no módulo Impima 5.0.2 do SPRING, conforme sugestão de DGI/INPE (2007), onde foram recortadas e salvas em extensão SPG.

As imagens restauradas passaram pelo processo de correção geométrica, a qual foi realizada através do registro. O mosaico Geocover foi aberto no aplicativo ENVI 4.3, teve o datum alterado e foi exportado no formato GeoTIFF, sendo recortada a área de interesse durante a mudança de extensão. A partir dessa base cartográfica foram identificados dez pontos notáveis para cada imagem, os quais serviram de pontos de controle, GCPs (Ground Control Points), realizando o registro de imagem para imagem. Adotou-se como padrão os erros de posicionamento inferiores a meio pixel. A projeção utilizada no registro foi a UTM, datum SAD-69, função polinomial de $2^{\mathrm{a}}$ ordem e interpolador "vizinho mais próximo". Após a correção geométrica foi efetuado o realce das imagens.

O realce da imagem compreendeu a escolha da tríade à composição colorida e a aplicação de realce de contraste. No primeiro caso, as bandas espectrais à composição RGB foi obtida a partir do cálculo do OIF (Optimum Index Factor), conforme Chavez Jr. et al. (1982). Os cinco tripletos mais bem classificados foram testados em composição RGB, sendo eleito o tripleto R4G5B1 para a aplicação de realce linear.

As imagens realçadas foram exportados em formato GeoTIFF e abertas no SIG ArcGIS 9.1, onde foi executada a vetorização das classes identificadas por interpretação visual. No mesmo aplicativo foram realizadas a formatação do layout, finalização e análise do mapa (FIG 2). 


\subsection{Identificação dos tensores}

Selye (1956 apud LUGO, 1978) define tensor como o estado pelo qual um organismo ou sistema passa e é condicionado à mobilização de recursos e ao aumento no gasto energético objetivando conservar ou restabelecer seu estado de equilíbrio dinâmico.

A identificação e caracterização dos indicadores de pressão antrópica presentes no manguezal do Rio Cachoeira foram realizadas a partir de observações em campo de elementos inseridos na paisagem que possam estar agindo como tensor ao ecossistema manguezal.

Com base no mapeamento realizado na etapa anterior e norteado pelo mapeamento da problemática ambiental da cidade de Ilhéus (CRA, 1994), foi elaborada uma lista de controle de campo (check list field) de impactos potenciais que poderiam estar ocorrendo sobre o ecossistema manguezal, tanto em sua periferia quanto dentro dos bosques. Estes foram fotografados com câmera digital (Olympus FE-100) e registrada a localização com GPS e Trex da marca Garmin.

\section{RESULTADOS E DISCUSSÕES}

Foram identificadas e mapeadas cinco classes temáticas (FIG. 2): manguezal, compreendendo as espécies típicas de mangue, independente do seu estado de conservação; água, que corresponde aos corpos lóticos e lênticos, à zona costeira e aos bancos de areia submergíveis; urbano, representando o ambiente construído e seu perímetro; mata e cabruca, sendo o primeiro em diferentes estágios de desenvolvimento (primária, secundária e em regeneração) e o segundo caracterizado pelo cultivo do cacau (Theobroma cacao L.) o qual utiliza árvores nativas remanescente de grande porte para o sombreamento do cacaueiro; e praia.

A partir do mapeamento das classes, pôde-se constatar a sua variação espacial ao longo do período em estudo.

A distância média dos manguezais à linha de costa é de aproximadamente $6.300 \mathrm{~m}$. Devido à con- fluência de mais dois rios, Santana e Itacanoeira, na foz do Rio Cachoeira, e conseqüente conjunção de algumas áreas de manguezal, foram realizadas esforços na tentativa de delimitar de modo expedito o limite destas áreas pertencentes ao Rio Cachoeira, com auxílio da cartografia disponível. Adotou-se como limite de cada rio os canais de escoamento preferenciais identificados nas imagens de satélite e confirmados em campo. Essa separação foi obtida com o intuito de se ter dados quantitativos de área para apreensão do grau de aumento ou diminuição da superfície dos manguezais e das demais categorias ou classes de uso do solo.

O ano de 1987 foi o primeiro analisado e mostra o início da ocupação do bairro Teotônio Vilela, situado ao norte dos manguezais da margem esquerda do Rio Cachoeira (FIG. 2A). Conforme Fidelman (2000), foi nessa década que se deu o início da ocupação deste espaço, e a presença antrópica se limitava à ocupação dos espaços vazios, não atingindo os manguezais do Rio Cachoeira que de certa forma atuava como barreira à expansão.

Apesar do estudo de Moreira \& Trevizan (2005) comprovar que a maioria dos habitantes desse bairro é procedente da zona urbana, diversas comunicações (FIDELMAN, 2000; MACEDO, 2001; ANDRADE, 2003; MARTINS, 2007) confirmam a crise da lavoura cacaueira como a principal responsável pela ocupação de manguezais no município de Ilhéus, podendo assim ser considerado um reflexo rural e não urbano, em face de ter sido conduzido pelos atores sociais expulsos do campo e emigrados para essa área.

De acordo com Silva (1996 apud FIDELMAN, 2000), a ocupação dos manguezais se deu devido à escassez de moradia e ao elevado preços dos poucos imóveis disponíveis, sendo a prefeitura conivente com essa prática que, no caso específico de bairro Teotônio Vilela, foi a promotora do aterramento e loteamento. Os indicadores de pressão nessa época são, possivelmente, o corte e aterro da vegetação.

A implementação do bairro pela própria prefeitura, a permanência da crise econômica baseada na 
Dinâmica de ocupação espacial de áreas contíguas (período 1987-2008) e sua relação com tensores de origem antrópica no manguezal do Rio Cachoeira, Ilhéus, Bahia

Patrick Thomaz de Aquino Martins, Lilian de Lins Wanderley
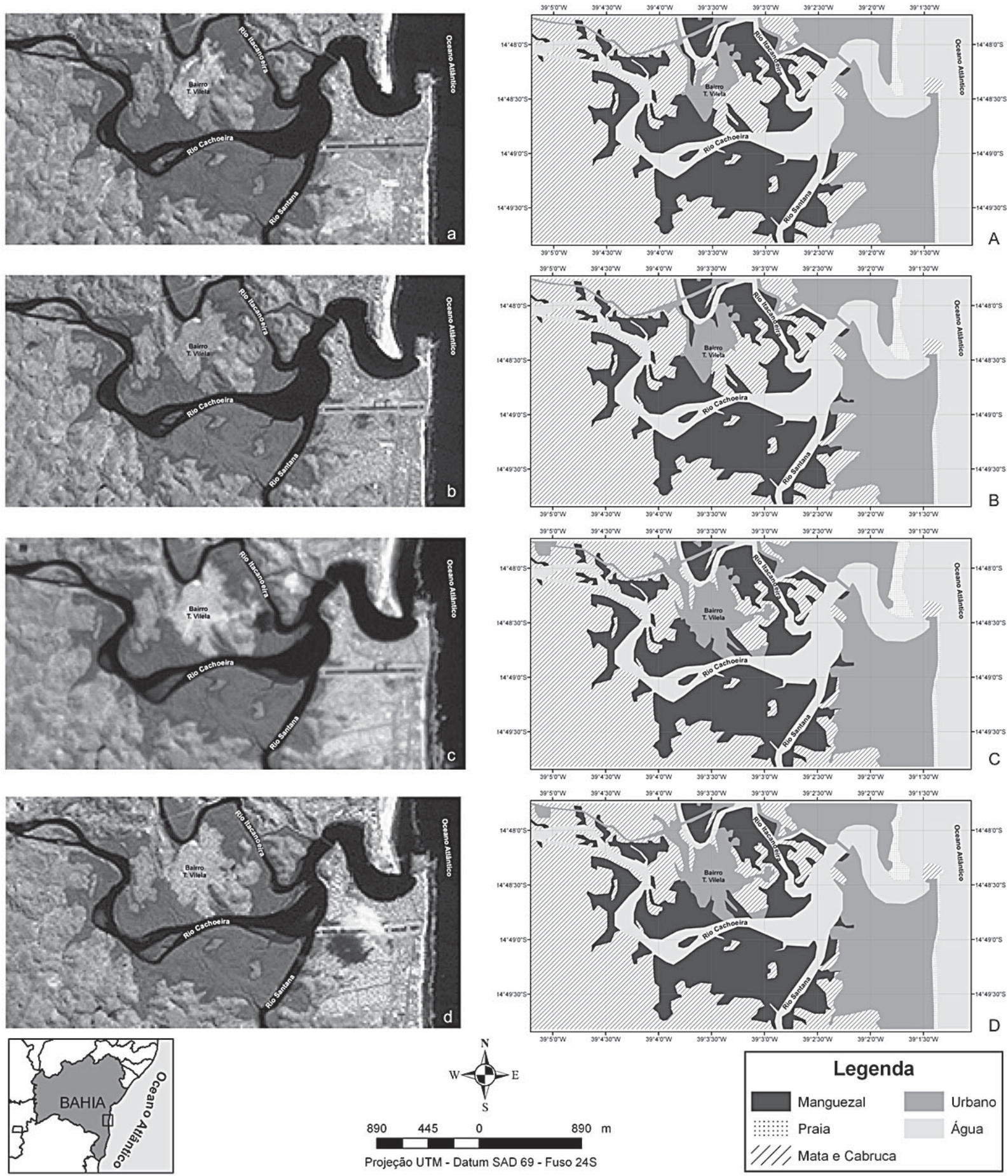

FIGURA 2. Modificações espaciais ocorridas no manguezal do Rio Cachoeira e áreas adjacentes. Imagem pré-processada e realçada (a $=1987, \mathrm{~b}=1994, \mathrm{c}=2001 \mathrm{e} \mathrm{d}=2008)$ e respectivos layouts dos anos avaliados (A, B, C, D).

monocultura do cacau e o crescimento demográfico do município que passou de 131.454hab. em 1980 (IBGE, 1982-1983) para 223.750ha. em 1991 (IBGE, 1991), serviram de fomento à continuação da ocupa- ção, por meio da invasão de áreas adjacentes aos manguezais e sobre o próprio ecossistema.

Ao longo da década predominou a ocupação 
por meio de invasão, aumentando assim a área do bairro e o avanço sobre os manguezais, como se pode ver na FIG. 2B, de 1994. Essa ocupação seguiu o seguinte padrão: as camadas mais carentes da população ocupam áreas que se valorizam com o estabelecimento de indivíduos de maior poder aquisitivo, os quais modificam a tipologia das habitações e forçam o deslocamento da população original para a periferia, em direção aos manguezais, considerada área de menor valor (SILVA, 1996 apud FIDELMAN, 2000).

Essas áreas ocupadas sofrem adensamento populacional, forçando os órgãos oficiais competentes a dar esse processo como fato consumado e irreversível. Interessados com a situação, as empresas de serviços públicos, como a de energia elétrica e transporte, implantam, mesmo que precariamente, equipamentos e infra-estruturas suficientes ao provimento dos serviços.

Aparentemente, esse padrão teve características diferenciadas apenas nos manguezais distantes do perímetro urbano, como, por exemplo, nos mangues do rio Cururupe, à cerca de $12 \mathrm{~km}$ da sede administrativa, conforme apurou Martins et al. 2008.
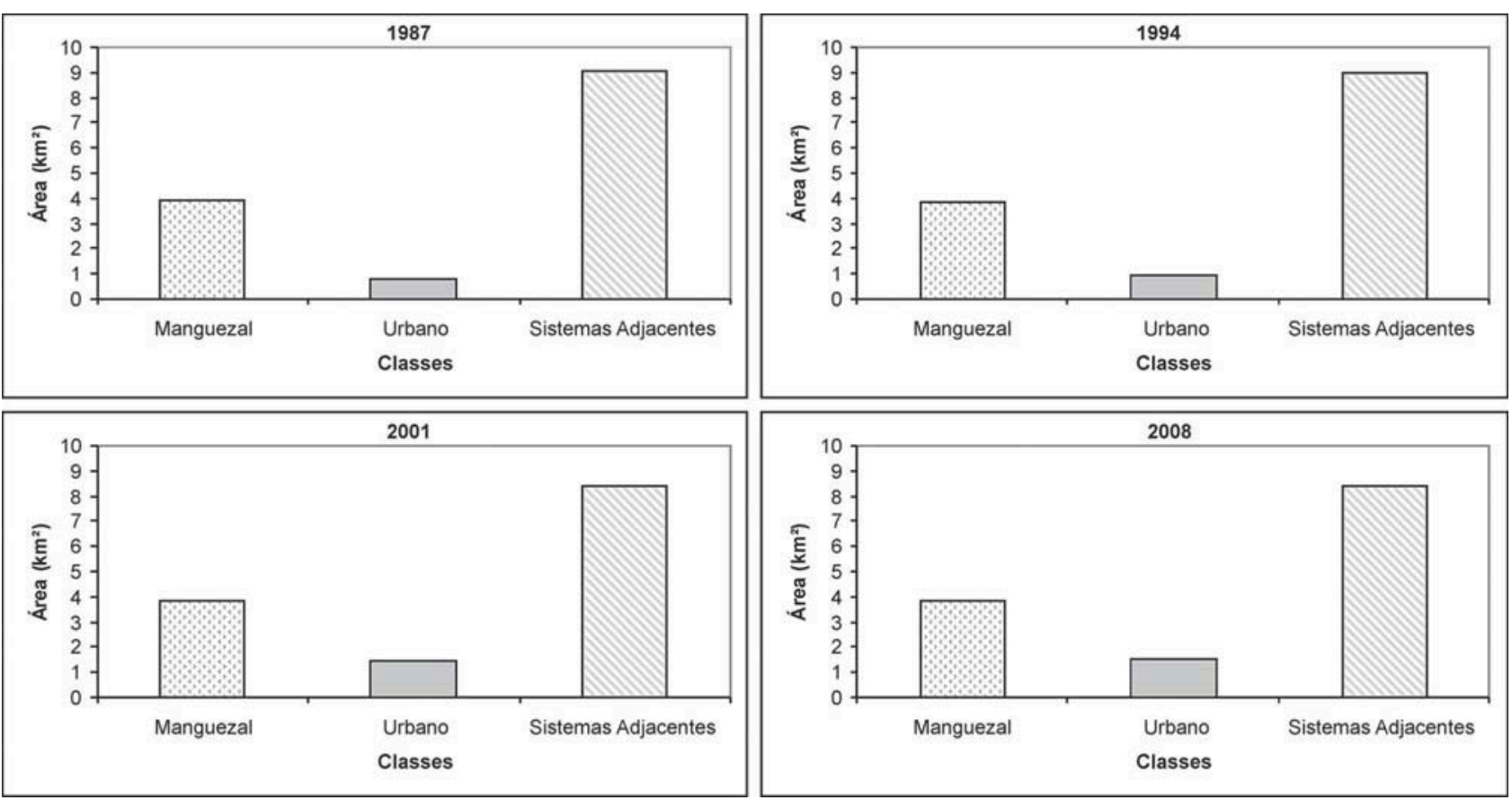

FIGURA 3. Variação de área $\left(\mathrm{km}^{2}\right)$ das classes identificadas durante o período estudado. 
Dinâmica de ocupação espacial de áreas contíguas (período 1987-2008) e sua relação com tensores de origem antrópica no manguezal do Rio Cachoeira, Ilhéus, Bahia

Patrick Thomaz de Aquino Martins, Lilian de Lins Wanderley

pesca e da mariscagem sem alterar, porém, o funcionamento normal do sistema.

O incentivo à conservação do patrimônio natural e à promoção do bem-estar das populações envolvidas na conservação são algumas das diretrizes do ecoturismo ou turismo ecológico, um dos segmentos do turismo, setor no qual o município se baseia como saída à estagnação econômica originária da crise da lavoura cacaueira. Paradoxalmente, não existem ações que beneficiem os manguezais em face da prática do ecoturismo. O cumprimento da legislação vigente por si só já deveria garantir a conservação ou preservação desse ecossistema no município.

Os últimos anos não tem sido diferente. A permanência da redução populacional do município, caindo para 220.144 (IBGE, 2008), não impediu a continuação do avanço sobre os manguezais (FIG. 2D). Os principais indicadores de pressão desse momento mapeado podem ser observados atualmente.
A alteração das áreas de mangue e seu entorno podem ser notadas na FIG. 3. Os valores de variação de área confirmam o que foi identificado no mapeamento.

A classe "urbano" foi a única que cresceu no período de 21 anos: 12ha de 1987 a 1994, 56ha de 1994 a 2001 e 4ha de 2001 a 2008. Em contrapartida, a classe manguezal teve sua área subtraída cerca de 2 ha por intervalo estudado.

O trabalho de campo permitiu a identificação dos impactos de impactos negativos e positivos.

Os impactos negativos são aqueles que agem como fator de stress no ecossistema. Contrariamente, os impactos positivos são os que favorecem de alguma forma o bom funcionamento do sistema Os impactos causados pelo homem podem acarretar alterações nas propriedades físicas, químicas e biológicas do manguezal. Esses impactos poderão se refletir diretamente

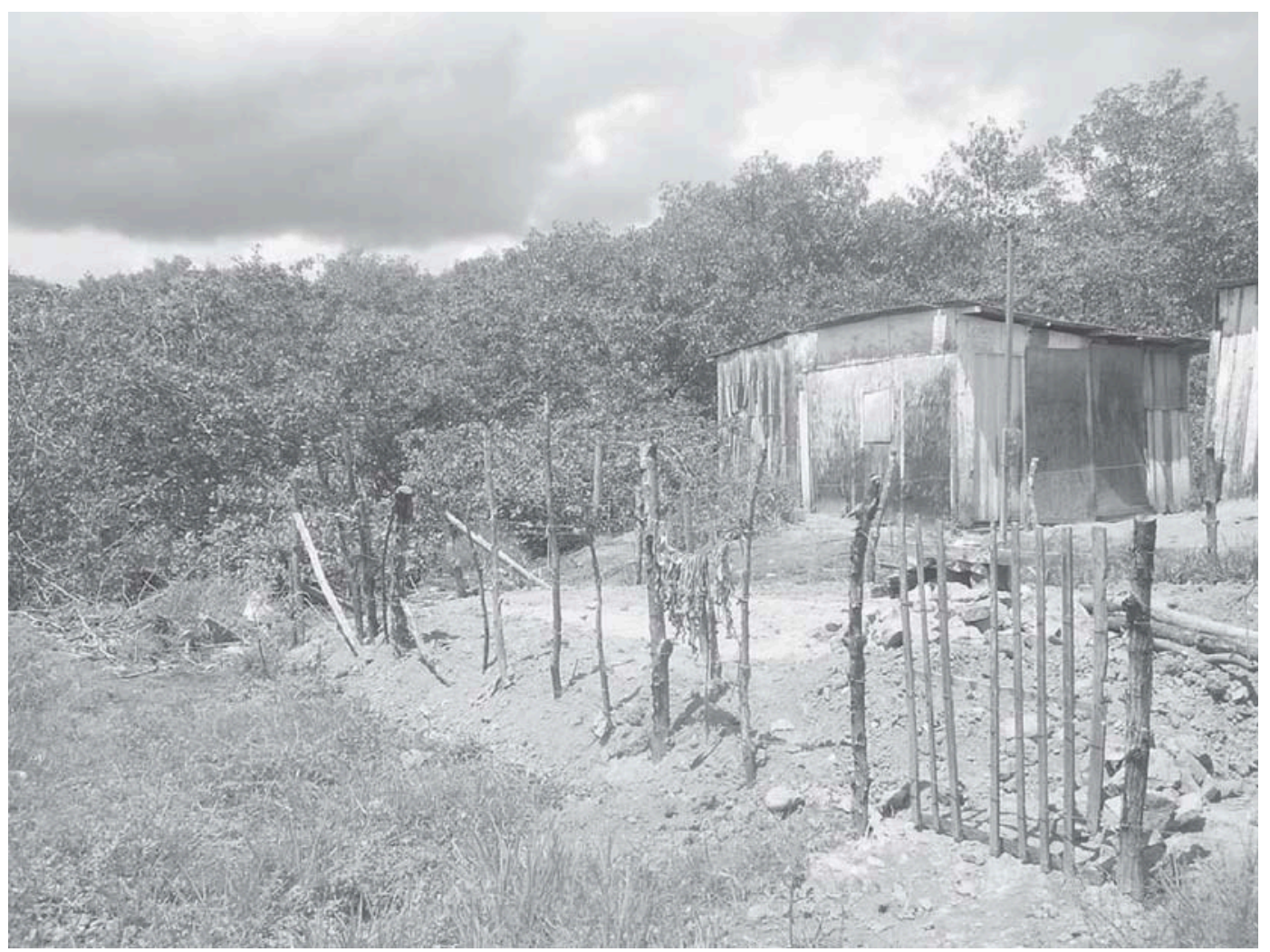

FIGURA 4. Aterro e construção sobre o manguezal. 
nas relações sócio-econômicas da população dependente desse meio.

Partindo do limite norte, onde há estreita relação com o perímetro urbano, podem ser observados os clássicos tensores iniciados com a invasão na década de 90. Na FIG. 4 se pode ver uma área aterrada sobre o manguezal, onde há uma habitação com baixa infra-estrutura e a delimitação territorial da propriedade. A presença do relógio de energia, ao lado da casa, demonstra, porém, o início da oferta de serviços básicos a esses habitantes, ajudando assim a legitimar a ocupação.

Nesse setor da área de estudo são notadas as origens de alguns detritos que são depositados para a construção da habitação e do arruamento, que podem ser tanto de sedimento terrígeno-argiloso (FIG. 4), quanto de entulho da construção civil e de resíduos orgânicos (FIG. 5). A compactação desse último faculta, inclusive, a produção do gás metano, que pode en- trar em combustão a partir do contato com o oxigênio.

O aterro é um dos impactos mais fortes à vegetação de mangue, pois elimina a vegetação por asfixia de suas raízes (FIG. 5), além de toda a fauna associada a esse ecossistema. Estes tipos de impactos podem, inclusive, representar a destruição direta do manguezal (VARJABEDIAN, 1995).

A dependência alimentícia e econômica que algumas famílias podem ter em relação a esse sistema é revelada pela presença de uma canoa (FIG.5). Essa vinculação é, por vezes, substituída pela presença de pequenas roças, onde são cultivados banana, mamão, abóbora, coco, dendê e outros alimentos.

O descaso dos órgãos públicos perante tal situação reflete-se na relação social dos habitantes do bairro. Apesar de usufruir de áreas atualmente bem urbanizadas, as comunidades apresentam um alto índice de violência e associação ao tráfico de entorpecentes.



FIGURA 5. Aterro constituído de resíduos sólidos à margem do manguezal. 
Dinâmica de ocupação espacial de áreas contíguas (período 1987-2008) e sua relação com tensores de origem antrópica no manguezal do Rio Cachoeira, Ilhéus, Bahia

Patrick Thomaz de Aquino Martins, Lilian de Lins Wanderley

Saindo do bairro e deslocando-se para noroeste da área de estudos foram identificadas importantes intervenções do poder público, sendo a rodovia BR415 (Ilhéus-Itabuna) a mais representativa.

A construção da BR-415 acarretou uma série de interferências ao manguezal do Rio Cachoeira. Além do aterro e corte da vegetação para a implantação da $\mathrm{BR}$, esta facilitou o acesso a algumas áreas de mangue, implicando na ocorrência de novas frentes de invasão. Obras de engenharia, aterro para construção de habitação, uso de detritos sólidos e corte da vegetação são as ações impactantes de maior peso e freqüência (FIG 6).

Em oposição aos manguezais da margem esquerda, os quais sofrem pressões tipicamente urbanas, os manguezais da margem direita do Rio Cachoeira são atingidos por impactos que não comprometem o bom funcionamento do sistema, constituindo-se como o único impacto positivo de todo o manguezal.

O difícil acesso via continente aos manguezais da margem direita do Rio Cachoeira é certamente o principal motivo pela não incidência de tensores nesse manguezal.

A presença de resíduos sólidos poderia estar associada às oscilações diárias das marés, a qual arrastaria esses detritos para o meio, onde ficaria retido devido à própria característica da vegetação. A alta freqüência de garrafas plásticas de bebida alcoólica em quase $100 \%$ dos mangues visitados, porém, quase que extingue essa hipótese, já que não se identificou essa homogeneidade com outros tipos de dejeto.

Um dado importante que se deve ressaltar é



FIGURA 6. Exemplos de intervenções à margem da BR-415: cortes de vegetação (A), obras de engenharia (B e D) e detritos sólidos (C). 
que, apesar da distância da cidade, existem ações que buscam proteger áreas adjacentes e acabam por contribuir para a conservação do manguezal. É o caso das RPPNs (Reserva Particular do Patrimônio Natural), no limite com o manguezal, em uma área de mata atlântica (Floresta Ombrófila Densa), e tem o objetivo de conservar a diversidade biológica a partir de uma unidade de conservação numa propriedade privada.

As propriedades que preservam remanescentes de mata atlântica, ou mesmo aquelas que ainda cultivam cacau, no sistema cabruca contribuem igualmente à conservação dos manguezais. A habitação rarefeita evita ou faz com que seja discreto o lançamento de resíduos líquidos e sólidos no sistema em questão.

Os impactos antrópicos incidentes sobre manguezal do Rio Cachoeira ao longo dos anos podem ter acarretado uma série de modificações no sistema. Fidelman (1999) discute as possibilidades ocorridas em um estuário próximo ao Cachoeira e junto ao Rio Santana, com um padrão de impacto análogo. Segundo o autor, os prejuízos possíveis são a redução da qualidade da água do estuário, da produtividade no sistema, dos habitats para espécies, da biodiversidade, do ciclo de vida de espécies aquáticas, nos valores estéticos e paisagísticos, dos usos tradicionais, do potencial turístico, da navegação, da recreação e da qualidade de vida da comunidade local.

A recuperação de áreas de manguezais degradados depende de alguns fatores, tais como, a disponibilidade em propágulos, a circulação hídrica e o nível de alteração ao qual foram submetidas. Todavia, existe um processo de recomposição natural que possibilita a volta da composição e estrutura naturais de qualquer ambiente, desde que a causa da destruição, total ou parcial, seja removida (VICENT, 1995).

No caso específico dos manguezais do Rio Cachoeira, o avanço das pressões antrópicas identificadas nos últimos anos e a atual situação vão contra essa possibilidade de regeneração natural. Mesmo que eliminado o fator stress, o metabolismo do sistema pode apresentar implicações negativas irreversíveis (GIAVENO \& OLIVEIRA, 2003).

\section{CONCLUSÕES}

A falta de informações sobre os aspectos dos manguezais do município é limitada, apesar da história de intervenções nesse meio e da flagrante ofensiva contemporânea. E esse fato se torna crítico, pois legitima, por omissão, as ações nesse ambiente.

A não diversificação dos produtos agrícolas do município, mantendo no cacau o principal cultivo, e a continuidade do êxodo campo-cidade em toda a região cacaueira podem ser apontadas como principais motivadores à ocupação dos manguezais do Rio Cachoeira.

A sobreposição de alguns fatores ligados às intervenções antrópicas, tais como o tempo de incidência, variabilidade espacial e característica deste, e as condições ambientais, sobretudo aqueles relacionados diretamente ao tipo de sedimento e ao acesso do corpo d'água à vegetação, influenciam diretamente a organização estrutural do manguezal do Rio Cachoeira.

Permanecendo o ritmo e a forma de alteração registrada nos últimos anos, as quais ainda perduram, associados à inatividade dos órgãos de combate a crimes ambientais, o cenário futuro previsto para esse ecossistema não é dos melhores.

Ações como a implantação de RPPNs e recuperação da mata ciliar em áreas do entorno do manguezal, assim como o reforço às bases econômicas ligadas ao ecoturismo devem ser incentivadas e implantadas, pois se tornam mais ferramentas de anteparo a ações degradantes ao manguezal.

O monitoramento da dinâmica espacial no entorno do manguezal, dos distúrbios conseqüentes e de parâmetros bio-geo-químicos do manguezal, do estuário e até mesmo da bacia hidrográfica, podem dar suporte à elaboração de um plano de conservação da vegetação de mangue: esta talvez seja a principal contribuição deste estudo, além da confrontação de informações e comparações com outras áreas estuarinas do litoral baiano. 
Geotecnologias de sensoriamento remoto, de GPS e SIG podem ser utilizadas como ferramenta de monitoramento do manguezal do Rio Cachoeira. Com o desenvolvimento de novos sensores e técnicas de mapeamento, essas tecnologias podem substituir, em parte, a etapa de fitossociologia.

O ganho de território sobre os manguezais do Rio Cachoeira dificilmente será interrompido nos próximos anos. O cumprimento da legislação, o planejamento urbano e a sensibilização coletiva poderiam mitigar ou mesmo cessar a transformação do espaço em áreas de manguezais. Enquanto isso não acontece, o município de Ilhéus ganha território e perde um ecossistema de inestimável valor, o que pode conduzir a mais problemas sociais num futuro próximo.

\section{AGRADECIMENTOS}

À Coordenação de Aperfeiçoamento de Pessoal de Nível Superior (CAPES), pela concessão de bolsa de Mestrado ao primeiro autor.

\section{REFERÊNCIAS}

ANDRADE, M. P. Ilhéus: Passado e Presente. 2. ed. Ilhéus: Editus, 2003.

CÂMARA, G. et al. SPRING: integrating remote sensing and GIS by object-oriented data modelling. Comput Graph, v. 20. p. 395 - 403, 1996.

CHAVEZ JR., P. S.; BERLIN, G. L.; SOWERS, L. B. Statistical method for selecting Landsat MSS ratios. Journal of Applied Photographic Engineering, v. 8, p. $23-31,1982$.

CENTRO DE RECURSOS AMBIENTAIS - CRA. Diagnóstico ambiental da cidade de Ilhéus. Ilhéus: CRA. 1994.

CUNHA, S. B. Bacias Hidrográficas. In: cunha S. B. Cunha \& GUERRA, A. J. T. (Orgs.), Geomorfologia do Brasil. Rio de Janeiro: Bertrand Brasil. p. $229-$ 271, 1998.
DIVISÃO DE PROCESSAMENTO DE IMAGENS/ INSTITUTO NACIONAL DE PESQUISAS ESPACIAIS - DGI/INPE. Tutorial de Geoprocessamento. Disponível em $<$ http://www.dpi.inpe.br $>$. Acesso em ago. 2007.

FIDELMAN, P. I. J. Diagnóstico como subsídio a um Gerenciamento Costeio: Estudo de Caso dos Manguezais do Rio Santana, Ilhéus, Bahia. 2000. 151f. Dissertação (Mestrado em Geografia Física) Faculdade de Filosofia, Letras e Ciências Humanas, Universidade de São Paulo, São Paulo, 2000.

FIDELMAN, P. I. J. Impactos causados por tensores de origem antrópica no sistema estuarino do rio Santana, Ilhéus, Bahia. In: Semana Nacional de Oceanografia, 12, 1999, Rio de Janeiro. Anais... 1999. p. 405 - 407.

GIAVENO, C. D.; OLIVEIRA, R. F. Estresse ambiental: Conceitos gerais. Sociedade Brasileira de Fisiología Vegetal, 2003.

GOOGLE. Google Earth. Disponível em: $<\underline{\text { http:// }}$ earth.google.com/intl/pt/>. Acesso em dez. 2007.

IBGE. Instituto Brasileiro de Geografia e Estatística. Censo Demográfico: dados distritais. Rio de Janeiro: IBGE. v. 1, tomo 3, n. 13. 1982/1983. 21p.

IBGE. Instituto Brasileiro de Geografia e Estatística. Censo Demográfico de 1991. Resultados do universo relativos às características da população e dos domicílios. Rio de Janeiro: IBGE, n. 17, 1991. 604p.

IBGE. Instituto Brasileiro de Geografia e Estatística. Cid@des. Disponível em <http://www.ibge.com.br/ cidadesat/default.php $>$. Acesso em jan. 2008.

LUGO, A. E. Stress and Ecosystems. In: THORP, J. H.; GIBBONS, J. W. (Eds.). Energy and Environmental Stress in Aquatic Ecosystems. DOE, Symposium Series. National Technical Information Service, Springfield, 1978. p. $62-98$.

MACEDO, I. O. Caracterização socioeconômica da população do bairro Teotônio Vilela. 2001. 68 p. Tra- 
balho de Conclusão de Curso (Graduação em Economia) - Universidade Estadual de Santa Cruz, Ilhéus, 2001 .

MARTINS, P. T. A. Os reflexos da crise da lavoura cacaueira nos ecossistemas de manguezal do município de ilhéus, Bahia. Geografia (Londrina), v. 16, n. 1, p. $39-49,2007$.

MARTINS, P. T. A.; COUTO, E. C. G. Distribuição das áreas remanescentes de manguezal do município de Ilhéus (Bahia - Brasil). In: CONGRESSO LATINO-AMERICANO DE CIÊNCIAS DO MAR, 12, 2007, Florianópolis. Anais... Florianópolis: AOCEANO, 2007. CD-ROM.

MARTINS, P. T. A.; COUTO, E. C. G.; DELABIE, J. H. C. Évolution récente de la zone estuarine d un microbassin côtier du Nordeste du Brésil soumis à différents types d impacts d origine humaine. Revue d'Écologie Terre et Vie, v. 63, p. 47 - 53, 2008.

MOREIRA, G. L.; TREVIZAN, S. D. P. O processo de (re)produção do espaço urbano e as transformações território-ambientais: um estudo de caso. Estudos Geográficos, Rio Claro, v. 3, n. 2, p. 78 - 90, 2005.

NATIONAL AERONAUTICS AND SPACE ADMINISTRATION - NASA. GeoCover. Disponível em: $<$ https://zulu.ssc.nasa.gov $/ \mathrm{mrsid} / \mathrm{mrsid} . \mathrm{pl}>$. Acesso em nov. 2006.

OLIVEIRA, M. C. R. As relações ambientais da bacia do Rio Cachoeira (Sul da Bahia). 1994. 102f. Monografia (Especialização em Geografia Física) Universidade Estadual do Centro-Oeste, Guarapuava, 1994.

OLIVEIRA, M. C. R. As relações ambientais da bacia do rio cachoeira sul da Bahia. Ilhéus: Editus, 1997. $112 \mathrm{p}$

PLANO NACIONAL DE GERENCIAMENTO COSTEIRO - PNGC. Brasília: Comissão Interministerial para os Recursos do Mar. 1990.
ROCHA FILHO, C. A. Recursos Hídricos. Rio de Janeiro: Carto-Gráfica Cruzeiro do Sul. Convênio IICA/ CEPLAC, 1976. 133 p. (Diagnóstico Sócio-Econômico da Região Cacaueira 5).

SUPERINTENDÊNCIA DE ESTUDOS ECONÔMICOS E SOCIAIS DA BAHIA - SEI. Consulta ao banco de dados. Disponível em <http://www.sei.ba.gov.br/ municipio/censo2000 result amostra/xls/demogra/ tx_cres.xls $>$. Acesso em jul. 2006.

SECRETARIA DO PLANEJAMENTO, CIÊNCIA E TECNOLOGIA / CENTRO DE ESTATÍSTICA E INFORMAÇÕES - SEPLANTEC/CEI. Informações básicas dos municípios baianos: região litoral sul. Salvador, 1996. 540p.

SUPERINTENDÊNCIA DE RECUSROS HÍDRICOS - SRH. Diagnóstico da Bacia do Leste. v. I, Tomo IV. Salvador: SRH. 1996.

VARJABEDIAN, R. Impactos sobre os manguezais. In: SCHAEFFER-NOVELLI, Y. Manguezal: Ecossistema entre a terra e o mar. São Paulo: Caribbebbean Ecological Research, 1995. p. $49-52$.

VICENT, R. C. Recuperação de manguezais degradados. In: SCHAEFFER-NOVELLI, Y. Manguezal: ecossistema entre a terra e o mar. São Paulo: Caribbean Ecological Research, 1995. p. 53 - 55. 